\title{
Use of Technology and Financial Literacy on SMEs Practices and Performance in Developing Economies
}

\author{
Juma Buhimila Mabula \\ Department of Business Administration, \\ Harbin Institute of Technology \\ Harbin, China
}

\author{
Han Dong Ping \\ Department of Accounting \\ Harbin Institute of Technology \\ Harbin, China
}

\begin{abstract}
Micro, Small and Medium Enterprises (SMEs) practices in developing economies experience a unique set of challenges to attain their success. With a view of analyzing double impact of SME financial literacy and use of technology on practice of record keeping and risk management as echoed on firm performance, the partial least square structural equation modelling was used to configure the perceived impact of these variables. The results posit a significant relationship between the firm use of technology to its practice of record keeping and performance, a significant positive association of financial literacy and firm risk management practices. Nevertheless the study found insignificant association of financial literacy and firm book keeping practice; it offers unleashed dual practical role of financial literacy and use of technology for improving SMEs financial practices in developing economies.
\end{abstract}

Keywords-Technology use; financial literacy; book keeping; risk management; developing economies

\section{INTRODUCTION}

As SMEs in developing countries being considered as important pillars of their economies they also serve as a mean for people's life sustenance and survival [1]. The fact that SMEs are managed by single or few owner/managers and their smallness nature implicate high cost of having relevant information as a base for rational decision making. Therefore possessing a well-placed technology utilization and financial literacy niceties can greatly enhance the firm decision making process.

The inception of new digital information and technology has revolutionized the world of business practices [2]-[4]. Besides of the challenges it has posed, the potential ample benefits justify its adoption by individuals and firms. The use of technology has an anchoring utility especially when it comes to learning process. Adopting new technology opens up multiple avenues for acquiring other skills and knowledge. In this quest the yielded results transmuted into business practices encompassing e-commerce, e-business and e-marketing. These practices has demonstrated a positive impact to all business of any size globally [5].

The analysis of the adoption and applicability of Information Communication and technology can only be meaningful if studied by satisfying the conditions for a company success [6]. Financial literacy as one of the basic gasp that is inevitable for an individual or firm has implacable anecdotes with the use of technology. Financial literacy and use of technology at individual and firm level has a tendency of bolstering each other. In [7], [8] embedding use of technology as a construct in financial literacy studies verify its noteworthy impact on firm financial practices and performance. At firm level the concept of financial literacy has been shown to have an influence on some basic firm practices [9]-[11] such that the attainment of improved financial literacy by the firm managers will ultimately improve the performance of the firm.

Coupled with the general low level of technological advancement, developing economies has shown a deviant picture in ICT adoption, while some countries have been able to yield the ICT potentials, other countries has lagged behind [12]. The choice of technologies is deemed to be the most important decision for developing economies, therefore understanding the intricacies for making such a choice is imperative [13]. On the other hand the general financial literacy in developing economies is also considered to be relatively low [14]. Therefore studying the double array of financial literacy and technology utilization impact on SMEs practices and performance forms an interesting phenomenon.

The use of technological at firm level reckoned to have positive impact on firm practices, and a financial literacy well placed firm managers provides an array for SMEs better financial management and improved performance. The analysis of concurrence and collectiveness of SMEs technology use with financial literacy impact on firm practice and performance is the focus of this study. Specifically this study improvise a model that works on assessing the impact of financial literacy and use of technology into firm record keeping practices and risk management replicating their consequential results on firm performance in developing economies.

\section{HYPOTHESIS DEVELOPMENT}

This study is based on an "evolutionary theory of economic change" by [15]. The theory contends that a firm searching for innovative (imitative) solutions boost their profits, in such a way prosperous firms grows at the expense of the outperformed firms. This process dynamically has an interaction of many variables in business competitive environment. Therefore the firms may not be able to grasp the finest technological bases, ultimately fail to heighten their performance perfectly.

The theory clearly shows the need for the firm to be innovative and the interactiveness of variables to boost the performance of the firm. The theory is applied to amplify the 
importance for right technology adoption as basis for improving firm performances. Technology enhances innovations and widen the sphere of knowledge and skills acquisition, the applicability of it is reflected in the firm interactive practices for enhancing its performance. With this base the general model is drawn and presented in Fig. 1.

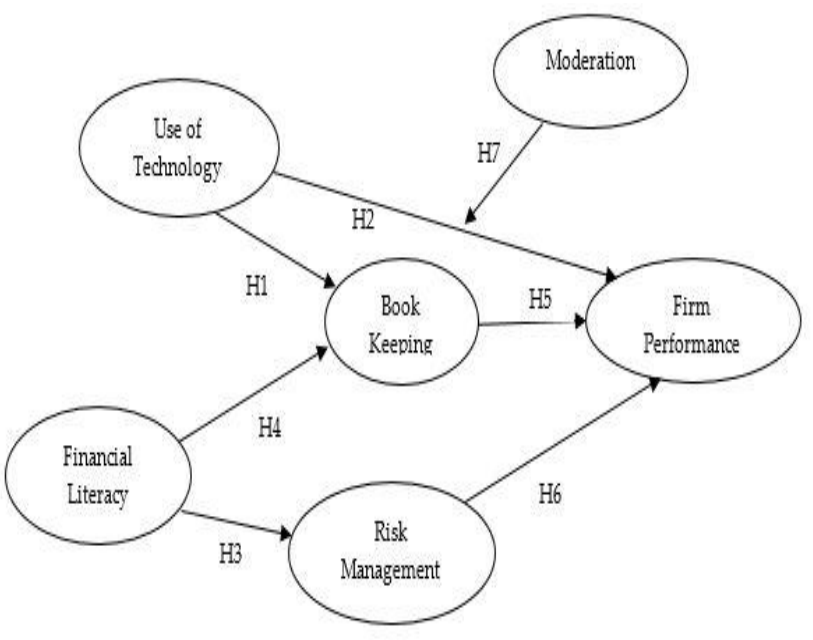

Fig. 1. The conceptual model of the study.

The application of information technology has had an obvious positive results into firm practices. [16] assert that firm with strong IT resources are able to assimilate the technological business planning cases more effectively, apprehend and make a dependable cost effective use that support the firm more fast than competitors, have an effective inter-business unity communications and able to foresee the future business needs before their competitors. The investment in information technology is a vital organization resource that can be used to advance communications, enhance product design worth, melt down the product development costs and lessen the design cycle [17]. Previous studies gives us a clue on the positive impact of information technology application on firm performance [16], [18], [19]. With this base the study therefore propose that:

Hypothesis $\mathrm{H}_{1:}$ The use of technology has a positive impact on firm practice of book keeping in developing economies.

Hypothesis $\mathrm{H}_{2}$ : The use of technology positively influence firm performance in developing economies.

Financial literacy at individual and firm level is a key to sound financial management. At a firm level, considering the nature of smallness of organizations, managers are easily capable of disseminating their financial knowledge and skills into firm practices. Financially literate SME manager is capable of using financial resources optimally, knows and understand the sources of reliable financing, capable of implementing sound business practices of budgeting, planning and control, put in place a sound system of acquiring, processing, storing and dissemination of financial information. The literature gives us ample overt evidences of financial literacy to financial practices [20]-[23] at individual level and [24]-[26] at firm level. Therefore researchers propose that:
Hypothesis $\mathrm{H}_{3}$ : Financial literacy positively influence the practice of risk management practices by SMEs in developing economies.

Hypothesis $\mathrm{H}_{4}$ : Financial literacy has a positive impact on firm book keeping practice in developing economies.

The SMEs functional practices are be a base of it success or failure. Of particular interest record management has been identified to be one of the principle success factor for entrepreneurs [27]. Therefore there is a need to have a comprehensive system prioritizing its authenticity. And enterprise risk management currently is viewed as one of the key conditions for successful firms because it enable them to put a glance at all risks facing a company through systematic plan [28]. Therefore SMEs are well placed to attain better performance if they have sound systems of record keeping and risk management. With these arguments it is proposed that:

Hypothesis $\mathrm{H}_{5}$ : The practice of book keeping positively influences the firm performance in developing economies.

Hypothesis $\mathrm{H}_{6}$ : The risk management practices in developing economies has a significant impact on firm performance in developing economies.

Author in [6] gives us clues that the information and technology is very crucial to SMEs because it enable them to implement their business competitive advantage. SMEs benefits by enhancing their visibility, easy access to information, overcome traditional trade areas and facilitate financial transactions. SMEs record keeping, processing and disseminations overtly enhanced by use of technology in terms of hard and software. The use of computers software enhances the preparation of instant periodical financial statements. Therefore SME use of technology in record management considered to increase the impact of firm use of technology on its performance. Therefore it is argued that:

Hypothesis $\mathrm{H}_{7}$ : Firm book keeping practices moderates the use of technology-firm performance relationship.

\section{LITERATURES}

\section{A. Financial Literacy}

Many individual has attempted to define financial literacy at personal level. The main focus has been simply summed up by Jump\$tart definitions who simply define financial literacy as the ability to use knowledge and skills to manage one's financial resources effectively. At firm level financial literacy stresses the ability of the owner/manager to be able to propagate their financial skills and knowledge into firm operations. The concept of financial literacy for SMEs spring from the nature of smallness and few owners of SMEs creating an avenue of easily transferring their expertise into firm endeavor. The Bank association of South Africa has attempted to define SME financial literate managers as entailing the following qualifications: having adequate level of entrepreneurial competencies, personal skills, and business management skills, having appropriate level of understanding of functional financial management systems, has appropriate level of understanding of SMEs life cycle funding and other financial requirements, understand legal, regulatory and tax issues as they relate to financial matters and understand the 
range of legal resources it can opt to when necessary, in case of bankruptcy or other financial distress situations [29].

\section{B. Use of Technology}

In this context [30] gives us a definition by stating that 'Information technology is the technology that is used to hoard, manipulate, distribute and create information'. [31] provides four dimensions of the use of technology readiness which are optimism, innovativeness, discomfort and insecurity. The optimism dimension presents a positive view of technology adoption and perception of the benefits to be accrued from its use for enhancing work efficiency and improving performance. Innovativeness refers to the extent to which individuals prefer to experiment with the new technology to come out with the best solution towards solving their problems. The dimension of discomfort displays a sense of lack of technological mastery and lack of courage to use the latest technology. And the insecurity dimension presents a state of complete mistrust of technology-based transactions and complete doubt of its capabilities. The first two dimensions are considered to be contributors to the process of adopting new technology while the last two represent inhibitors of the technological adoption. Author in [32] shows that optimist and innovators are prone to adopting to new technology easily. In terms of financial supply technology advances is the ability to effortlessly create a free online connection structure, the secure online money transfer, correct credit scores to be utilized by a bunch of financiers, and the free media tools to market their products therefore engage large group of geographically dispersed people [33].

\section{SMEs Definition}

Defining SMEs has been a contextual endeavor due to lack of general widely accepted definition. The study define SMEs by Tanzania context the setting of where the study was undertaken. The Tanzania SME policy defines SME to mean micro, small and medium enterprises. These organizations comprises of non-farm activities mainly manufacturing, mining, commerce and services. The micro organizations are those employing up to 4 people with capital threshold of Tanzanian shillings 5.0million. The small enterprises are considered to employ ranging from 5 to 49 human resources with capital investment ranging from Tshs. 5 million to Tshs. 200 million. The medium enterprise they are the one which employ between 50 to 99 people within a range of capital of Tsh.200 to 800 million [34].

\section{Use of Technology and Financial Literacy}

The adoption of technology by individual and firm now has become an inevitable matter boosted by expanded coverage and presence of wireless cellphones, computers, internet and other gadgets. In developing economies where there is prevalence of low level of technology, the use of technology has become a pillar for individual and firm success. The connection of technology and financial products offers crucial tie on enhancing financial literacy. For instance the electronic banking which has proliferated recently has increased financial products consumers' accessibility. These technological products may include direct deposit, computer banking, store value cards and debit cards [35]. A study of financial literacy by [8] on financial literacy of micro entrepreneurs in South Africa found that there is a limited use of technology by most firms. In this study they discovered that most of the firms had no email address and inaccessibility to internet at their work station, none of their respondents had a webpage. Financially excluded individuals and firms suffer from lack of financial literacy and basic education resulting into limited access into financial services. Therefore concentrate much on the use of informal financial system of which they are more familiar with. The barrier can be bypassed by employing information technology, which gives a feasible option to reduce transaction costs at large extent and form user friendly platforms convenient to the users [36].

\section{E. Use of Technology SME Practices}

The general extent of utilization of technology by SMEs is at low level [37]. Nonetheless literature offer ample evidence that utilization of technology is an important determinant for SME success [38]-[40]. Considering the scale of many small businesses such that they are more prone to cash flow problems, and therefore have less resources to devote to the sophisticated management of financial instruments and, since they don't partake into economies of scale and market power enjoyed by large organizations [41], [42]. The use of information technology by SMEs can benefit them by developing competences for managing, information intensive resources, reduce the transaction costs and develop capability to gather information locally and internationally resulting into rapid flow of information [30]. For instance crowd funding via internet based forums can improve SMEs access to finance and potentially remedy certain market failure, such as sufficiency of funding for start-ups it is a flexible, cost-effective and quickly raise finances, and it could be a marketing tool to entrepreneurs [43].

\section{F. SMEs use of Technology and Record Keeping}

Firm records are business information that contains the transactions between parties in the form of electronic and paper documents kept for present and future references [44]. The electronic business records, refers to the records in a form of digital records processed, manipulated and/or transmitted using a computer system. The practice of keeping information electronically by SMEs poses a new set of challenges for the SMEs to retain the authenticity of such information because they can easily be altered.

\section{G. Financial Literacy and SMEs Risk Management}

Authors in [45] stresses the importance of insurance as the main driving risk tool for SMEs because the other sophisticated means of risk management might prove to be cost ineffective. Financial literacy enables individuals and businesses to make better financial decisions and therefore undertake firm risk management more effectively [8].

Author in [46] measuring financial literacy discovered one's protection from unexpected happenings using either insurance or risk management techniques is one of the important constructs in financial literacy studies. Risk management is an interdisciplinary theme which may call integration of knowledge of fields of economic, technological, social and political knowledge. SME managers function in a macro, and micro market environment that is affected by numerous internal and external influences which continuously 
prone to change. The situation confronts entrepreneurs to be vigilant therefore able to identify opportunities and threats. Having more knowledge of financial literacy specifically in strategic risk management enables SMEs owner/managers to objectively evaluate their actions. The challenge with risk management is that every risk is linked to a different discipline which may not be necessarily in conversancy of firm manager proficiency. The concept of managing risks is an essential part of borrowing and investing. Therefore risk management is considered as part and parcel of individual and firm financial literacy.

\section{METHODOLOGY}

Data was collected through a survey of SMEs in region of Morogoro and Dar es salaam region Tanzania. The survey was directed to SMEs owners/managers' at the top level who could provide the required information. The data collection was done by researchers' personal visit at the firm location and the researcher supervised the process of filling the questionnaire for prompt response. The introduction was preceded by the introduction letter assuring the participants that the information needed was solely academical, confidential treatment of the results and researchers' readiness to avail the results to them and the public at large. The choice of firm to be included in this study was based on convenient sampling due to limiting factors including firm proximity, time, financial and respondents readiness. The survey was done by a team of 4 researchers with an average of 8 SMEs reached per day per each researcher. The researcher visited 520 firms and the complete usable results obtained from 311 firms. A response rate of about 60 percent. This study is part of the comprehensive questionnaire designed capture main aspect of financial literacy at personal and firm level. The survey questionnaire was used in pilot study for instruments refinements and then evaluated by experts. Cronbach's alpha test was used to verify its quality and consistency. Basing on the PLS sampling rule that the minimum sample size has to be ten times of the portion the model that require for multiple regression. This model has 5 independent variables tolerating the use a minimum sample of 50 , therefore 311 is more than six times enough.

\section{A. Measured Variables}

The indicators making up the constructs for financial literacy were gathered using instruments validated by [14] where by financial literacy (FL), was categorized into general financial knowledge, financial knowledge, financial attitudes, and financial behavior. Financial knowledge was captured using multiple choice questions and the remaining questions of financial attitudes and behavior were stylized into a likert scale, the choice of questions was made in such a way they are relevant to firm level business operation. The use of technology (UT), book keeping (BK) and risk management (RMGT) were are all adopted from [8], thereafter made into likert scale questions of 5 points. Some items were added from the original format questions for questionnaire comprehensiveness. The firm performance (FP) indicators was drawn from the enterprise survey questionnaire, formed into a five point likert scale, [47] uses the same approach.

\section{B. Demographic Information}

The study captured demographic information at individual and firm level. At individual level the survey collected information about gender and education level and at firm level information collected was about business type, location, firm age and number of employees. Table I shows the detailed results. The demographic information were used as control variables. These control variables were linked to the independent variables and assessed whether there was a significant increase in $\mathrm{R}$ square, the results with all control was insignificant, therefore the influence of these control variables was excluded in further analysis.

TABLE I. SUMMARY OF RESPONDENTS DEMOGRAPHIC INFORMATION

\begin{tabular}{|l|l|l|l|}
\hline \multirow{3}{*}{ Gender } & & Number & Percentage \\
\hline \multirow{5}{*}{ Education Level } & Male & 164 & 52.9 \\
\cline { 2 - 4 } & Female & 146 & 47.1 \\
\hline \multirow{5}{*}{ Business type } & Primary & 11 & 3.5 \\
\cline { 2 - 4 } & Secondary & 87 & 28.1 \\
\cline { 2 - 4 } & College & 134 & 43.2 \\
\cline { 2 - 4 } & University & 78 & 25.2 \\
\hline & Wholesale and Retail & 101 & 32.2 \\
\cline { 2 - 4 } & Agricultural & 56 & 18 \\
\cline { 2 - 4 } & Construction & 31 & 10.0 \\
\cline { 2 - 4 } & Food and & 31 & 10.0 \\
\cline { 2 - 4 } & Accommodation & 30 & 9.7 \\
\cline { 2 - 4 } & Manufacturing & 61 & 19.1 \\
\cline { 2 - 4 } & Others & 127 & 41 \\
\hline \multirow{4}{*}{ Focation } & Rural & 183 & 59 \\
\cline { 2 - 4 } & Urban & 39 & 12.6 \\
\hline \multirow{5}{*}{$\begin{array}{l}\text { Number of } \\
\text { employees }\end{array}$} & Below 1 Year & 132 & 42.6 \\
\cline { 2 - 4 } & 1-5 Years & 100 & 32.3 \\
\cline { 2 - 4 } & 6-10 Years & 39 & 12.6 \\
\cline { 2 - 4 } & More than 10 Years & 144 & 46.5 \\
\hline & 1-5 Micro & 147 & 47.4 \\
\cline { 2 - 4 } & 6-49 Small & 19 & 6.1 \\
\cline { 2 - 4 } & 50-99 Medium & \\
\hline
\end{tabular}

\section{Examination of Model Reliability and Validity}

By examining the parameters of the PLS structural model the hypotheses are assessed. The standardized path coefficients shows how strong the relationship between the independent and dependent variable. In a partial least square- structural equation modelling composite reliability is an alternative preference to Cronbach's alpha to test the convergent validity in a reflective model, this is because Cronbach's alpha may under/overestimate the scale of reliability [48].

The first step was to examine the outer model acceptability in the research algorithm. The outer loading acceptable range be $\geq 0.5$, [49]-[52]. According to the result presented in a Table II, all of the construct meet this criterion with exception of UT3 and therefore considered further analysis.

Average variance extracted (AVE) can be used to assess both convergent and divergent validity. In actual fact AVE mirrors the average communality for every latent factor in a reflective model. The AVE can be calculated by having the sum squared component loading for each construct divided by sum of component loading plus the sum of the error variance. The adequacy of a model is reflected by AVE being greater 
than 0.5 [49], [53]. The meaning of this condition is that factors in the model at least explain half of the variance of the corresponding indicators. Once more Table II presents acceptable results for the model.

TABLE II. RELIABILITY AND CONVERGENT VALIDITY

\begin{tabular}{|c|c|c|c|c|}
\hline & Mean & $\begin{array}{l}\text { Standard } \\
\text { Deviation }\end{array}$ & Loading & t-static \\
\hline & \multicolumn{4}{|c|}{ Book keeping (composite reliability $=0.765 ; A V E=0.5$ ) } \\
\hline BK1-BK & 0.649 & 0.225 & 0.706 & $3.257 *$ \\
\hline BK2-BK & 0.715 & 0.225 & 0.771 & $3.639 * *$ \\
\hline BK3-BK & 0.612 & 0.225 & 0.635 & $2.812 *$ \\
\hline \multirow[t]{2}{*}{ BK4-BK } & 0.543 & 0.225 & 0.561 & $3.142 * *$ \\
\hline & \multicolumn{4}{|c|}{ Use of technology (composite reliability $=0.762 ; A V E=0.5$ ) } \\
\hline UT1-UT & 0.794 & 0.149 & 0.829 & $6.222 * *$ \\
\hline UT2-UT & 0.788 & 0.165 & 0.826 & $5.926 * *$ \\
\hline \multirow[t]{2}{*}{ UT3-UT } & 0.443 & 0.271 & 0.469 & 1.783 \\
\hline & \multicolumn{4}{|c|}{ Financial Literacy (composite reliability $=0.794 ; A V E=0.5$ ) } \\
\hline GFL-FL & 0.476 & 0.201 & 0.537 & $5.599 * *$ \\
\hline FA-FL & 0.772 & 0.151 & 0.795 & $4.627 * *$ \\
\hline FK-FL & 0.772 & 0.156 & 0.814 & $4.860^{* *}$ \\
\hline \multirow[t]{2}{*}{ FB-FL } & 0.620 & 0.201 & 0.637 & $3.061 *$ \\
\hline & \multicolumn{4}{|c|}{ Firm Performance (composite reliability $=0.803 ; A V E=0.6$ ) } \\
\hline PF1-PF & 0.916 & 0.135 & 0.947 & $10.770 * *$ \\
\hline PF2-PF & 0.647 & 0.227 & 0.703 & $3.472 *$ \\
\hline \multirow[t]{2}{*}{ PF3-PF } & 0.602 & 0.179 & 0.601 & $3.205^{* *}$ \\
\hline & \multicolumn{4}{|c|}{ Risk Management(composite reliability $=0.817 ; A V E=0.6$ ) } \\
\hline $\begin{array}{l}\text { RMGT1- } \\
\text { RMGT }\end{array}$ & 0.832 & 0.169 & 0.891 & $4.860^{* *}$ \\
\hline $\begin{array}{l}\text { RMGT2- } \\
\text { RMGT }\end{array}$ & 0.642 & 0.256 & 0.692 & $2.510^{*}$ \\
\hline \multirow[t]{2}{*}{$\begin{array}{l}\text { RMGT3- } \\
\text { RMGT }\end{array}$} & 0.674 & 0.258 & 0.728 & $2.925^{*}$ \\
\hline & \multicolumn{4}{|c|}{$* \mathrm{p} \leq 0.05$ and $* * \mathrm{p} \leq 0.001$} \\
\hline
\end{tabular}

1) Discriminant validity

The Fornell-Larcker criterion was used to establish the discriminant validity. The criterion is based on calculation of AVE. which states that "for any latent variable, the square root of the AVE should be higher than its correlation with any other latent variable" [48]. This imply that for any latent variable the shared variance with its cluster of indicators is higher than the variance it shares with any other latent variable. In result Table III verify that there is discriminant validity in the model since all the numbers in diagonal cells (square root of AVE) in absolute terms are greater than the corresponding correlation of the variables.

TABLE III. FORNEL-LARCKER CRITERION AND HETEROTRAITMONOTRAIT RATIO (HTMT) IN PARENTHESIS

\begin{tabular}{|l|l|l|l|l|l|}
\hline & BK & FL & FP & RMGT & UT \\
\hline BK & 0.673 & & & & \\
\hline FL & $-0.164(0.3)$ & 0.705 & & & \\
\hline FP & $0.35(0.6)$ & $\begin{array}{l}0.014 \\
(0.2)\end{array}$ & 0.764 & & \\
\hline
\end{tabular}

\begin{tabular}{|l|l|l|l|l|l|}
\hline RMGT & $-0.020(0.3)$ & $\begin{array}{l}-0.269 \\
(0.4)\end{array}$ & $0.112(0.3)$ & 0.775 & \\
\hline UT & $-0.243(0.5)$ & $\begin{array}{l}-0.110 \\
(0.3)\end{array}$ & $-0.269(0.5)$ & $\begin{array}{l}0.007 \\
(0.1)\end{array}$ & 0.728 \\
\hline
\end{tabular}

2) Cross loading and heterotrait-monotrait ratio

An alternative to assessing discriminant validity beside of AVE is the examination of the cross-loading. Accordingly a good model has to have indicators which load well on their intended factors. The cross loading with other factors they are not intended to measure should be given attention. The rule of thumb is that cross loading should be under 0.3 and some use 0.4 [48]. Evaluating the variables in Table IV, all indicators have less or equal to 0.3 cross loading weight signifying that the model has discriminant validity.

Superior to the use of cross-loading examination and use of Fornell-Larcker criterion the heterotrait monotrait ratio (HTMT) criterion was established. The HTMT is the geometric mean of the heterotrait-heteromethod correlation divided by the average of the monotrait-heteromethod correlations [54]. The condition for this criterion for a well-fitting model, heterotrait correlations should be smaller than the monotrait correlations, implying that the HTMT ratio should be below 1 . A cut of 0.9 is established in literature [55], [56]. The results from model in Table IV shows all ratios displayed are fine below 0.9, again further confirming that the model has discriminant validity.

TABLE IV. VARIANCE INFLATION FACTOR (VIF) AND CROSS LOADING

\begin{tabular}{|c|c|c|c|c|c|c|}
\hline & \multirow[t]{2}{*}{ VIF } & \multicolumn{5}{|c|}{ Cross Loading } \\
\hline & & $B K$ & $F L$ & $F P$ & $R M G T$ & $U T$ \\
\hline BK1 & 2.196 & 0.7 & -0.1 & 0.2 & 0.0 & -0.2 \\
\hline BK2 & 2.234 & 0.8 & 0.0 & 0.3 & -0.2 & -0.3 \\
\hline BK3 & 1.264 & 0.6 & -0.3 & 0.3 & 0.1 & -0.0 \\
\hline BK4 & 1.264 & 0.6 & -0.1 & 0.2 & -0.0 & 0.0 \\
\hline FA & 1.629 & -0.2 & 0.8 & -0.0 & -0.1 & -0.1 \\
\hline FB & 1.617 & -0.1 & 0.6 & -0.1 & -0.1 & -0.1 \\
\hline FK & 1.010 & -0.0 & 0.8 & 0.2 & -0.3 & -0.1 \\
\hline GFL & 1.061 & -0.2 & 0.5 & -0.0 & -0.2 & -0.0 \\
\hline PF1 & 2.089 & 0.3 & 0.0 & 0.9 & 0.1 & -0.3 \\
\hline PF2 & 1.669 & 0.2 & -0.0 & 0.7 & 0.2 & -0.2 \\
\hline PF3 & 1.572 & 0.3 & -0.2 & 0.6 & -0.0 & -0.1 \\
\hline RMGT1 & 2.649 & -0.1 & -0.3 & 0.1 & 0.9 & -0.0 \\
\hline RMGT2 & 1.870 & -0.0 & -0.2 & -0.0 & 0.7 & 0.0 \\
\hline RMGT3 & 1.846 & 0.0 & 0.1 & 0.2 & 0.7 & -0.0 \\
\hline UT1 & 2.286 & -0.3 & -0.1 & 0.1 & 0.0 & 0.8 \\
\hline UT2 & 1.331 & -0.2 & -0.1 & -0.2 & 0.0 & 0.8 \\
\hline UT3 & 1.874 & -0.2 & -0.1 & -0.2 & 0.0 & 0.5 \\
\hline
\end{tabular}

3) Multicollineariry

The possibility of multicollinearity existent in the reflective model was also tested. Multicollinearilty occurs when two or more variables are highly intercorrelated. This may deter a researcher from assessing the relative importance of the independent variable. To examine the presence of 
multicollinearity a variance inflation factor (VIF) is used. The common rule of thumb provides a cut off of 4 or higher VIF for multicollinearity to exist [48]. In this model the results in Table IV offers all indicators VIF below 4 signifying that multicollinearity hasn't affected this scrutiny.

\section{4) Common method bias}

In a survey model of self-reported data there is a possibility of common method bias to exist. [57] posit that common method bias can be a result of a combination of many factors that may entail consistency and social interest. Specifically common method bias is a caused by the measurement approach used in a structural equation modelling study and the implied social desirability associated with the questionnaire responses eliciting the indicators to share a certain amount of conjoint variation [58]. To assess whether the data are affected with common method bias two approaches were employed, first is the psychological separation [59] done during data collection the questionnaire was structured in such a way the dependent and independent variables question was not asked on chronological order. Secondly was to further asses the data collected in the model using the approach by [58]. The approach emphasize on assessing the variance inflation factor (VIF) acceptability say if they are $\geq 3.3$ provided that the data passed the convergent and discriminant validity then confirm the absence of common method bias problem in the model. Table IV verify VIF results in the model are below 3.3, therefore it validate that the data are not affected by common method bias.

\section{Evaluation of Study Structural Model}

With satisfactory measurement model and no worry for multicollinearity, common method bias and the non-response biases the analysis proceeded to test the study structural model. The test comprises of estimates of path coefficients signifying the strength of the relationship between dependent and independent variable and the evaluation of the significance of such path coefficients.

TABLE V. PATH COEFFICIENT

\begin{tabular}{|l|l|l|l|l|}
\hline & Sample & Mean & $\begin{array}{l}\text { Standard } \\
\text { deviation }\end{array}$ & T statistics \\
\hline BK->FP & 0.372 & 0.371 & 0.116 & $3.134^{* *}$ \\
\hline FL->BK & -0.193 & -0.208 & 0.153 & 1.227 \\
\hline FL->RMGT & 0.269 & 0.287 & 0.125 & $2.227^{*}$ \\
\hline ModE->FP & 0.195 & 0.174 & 0.093 & $2.075^{*}$ \\
\hline RMGT->FP & 0.113 & 0.117 & 0.144 & 0.790 \\
\hline UT->BK & 0.264 & 0.285 & 0.121 & $2.273^{*}$ \\
\hline UT->FP & 0.197 & 0.204 & 0.095 & $2.065^{*}$ \\
\hline$* \mathrm{p} \leq 0.05$ and $* * \mathrm{p} \leq 0.001$ & & & \\
\hline
\end{tabular}

Examination of the specific hypotheses exemplified in the study model was assessed by two-tailed t-statistics for the standardized path coefficients running basic bootstrap with no sign changes option at 1000 samples. The results are shown in Table V and Fig. 2.

$\mathrm{H}_{1}$ Predicted the presence of positive direct relationship between the firm use of technology and the practice of firm book keeping in developing economies. The PLS structural path coefficient was significant at $(p<0.05)$ in hypothesized direction. This proposes that firm which has the high rate of use of technology are the one with improved of record keeping practices. Therefore $\mathrm{H}_{1}$ is supported.

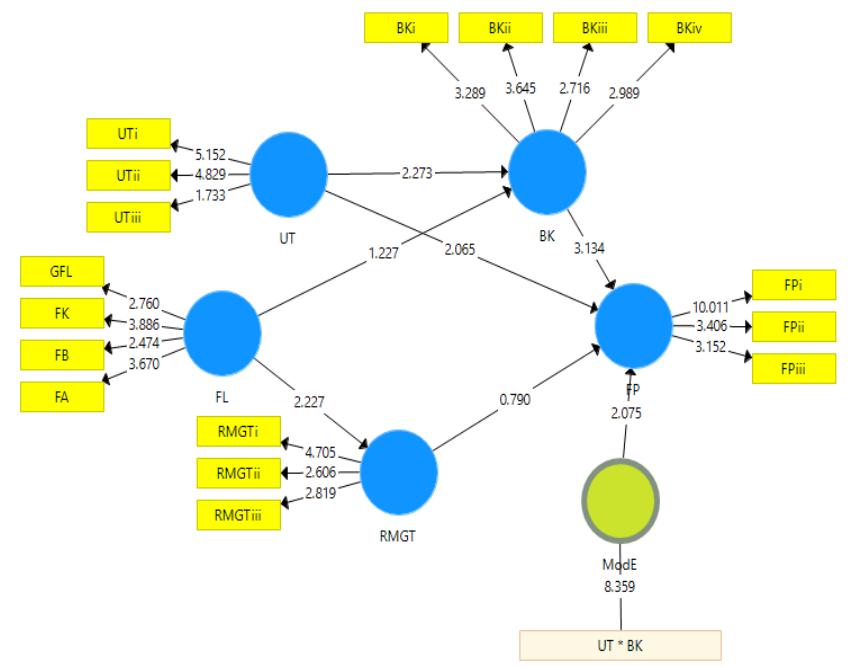

Fig. 2. Results after bootstrap.

$\mathrm{H}_{2}$ Also predicted a positive relationship of the firm use of technology with its performance. According to the results the PLS structural path coefficient on this relationship was significant at $(\mathrm{p}<0.05)$ on the positive hypothesized direction. The results suggests that the more the firm employ the use of technology the more it will improve its performance over a steady period of time. Therefore $\mathrm{H}_{2}$ is supported by the study algorithm.

$\mathrm{H}_{3}$ States that financial literacy has a positive relationship with firm risk management practices. From the results the PLS structural path coefficient confirm that this path is significant at $(\mathrm{p}<0.05)$ again the result suggest that, the higher the financial literate managers the more likely to engage into risk management of the firm. Therefore financial literacy of those who manage the SMEs in developing economies has an important impact on firm risk management. Again $\mathrm{H}_{3}$ is supported by the algorithm.

$\mathrm{H}_{4}$ suggested that there is positive relationship between financial literacy and firm practice of record keeping. The PLS structural path coefficient in this it is not significant. Suggesting that there is no direct relationship between financial literacy and the practice of book keeping. Though it is hard to draw a conclusion on insignificant results speculation can be on factors like the managers' level of education and factors for financial information flow constructs may mediate or moderate the relationship between financial literacy and firm book keeping practice.

$\mathrm{H}_{5}$ predicted that there is positive relationship between firm practice of book keeping and firm performance. The partial least square structural path coefficient is significant at $(\mathrm{p}<$ 0.01 ) in a hypothesized direction. The results indicate that, the more the firm put more emphasis on practice of record keeping the more will enhance its performance over time. This higher significance emphasize on how important record keeping can 
be for firm sustainability. Keeping records is the base of all analysis aiding financing, investment, marketing and pricing decisions. Therefore $\mathrm{H}_{5}$ is supported by the analysis.

$\mathrm{H}_{6}$ predicts that there is a direct positive relationship between firm risk management practices and firm performance. The PLS structural path coefficient in this equation is not significant though it display a positive relationship. With this results speculation can be that there are other factors that mediate/moderate the risk management-firm performance relationship. The risk management factor determinants also would be not likely to be captured in a short while because the happening of uncertain event is not certain. Therefore $\mathrm{H}_{6}$ is not supported.

$\mathrm{H}_{7}$ Predicted the moderating role of firm book keeping practice on use of technology-firm performance relationship. The PLS structural path coefficient is significant on this equation at $(p<0.05)$. The result suggests that firm practice of record keeping enhance the relationship of firm use of technology and its performance in developing economies. In other words emphasizing on plausible firm record keeping practice implicate more use of technology which eventually improve firm performance. Therefore $\mathrm{H}_{7}$ is supported by the analysis.

\section{DisCUSSION OF RESUlTS}

This study links variables at individual and firm level, examining how financial literacy and use of technology affect the business practices of book keeping and risk management translating the ultimate effect on firm performance in developing economies. The results presents significant results on the impact of use of technology and firm practices and performance. This result is consistent [38]-[40], [60]. Adoption and actual use of more sophisticated information technology system technology of more sophisticated in developing countries would have a cunningly better way of SMEs practices and performance.

Enhancing financial literacy of SMEs managers in developing economies still proves its vitality. Even though the model offer a slight insignificant results of $(p<0.2)$ suggesting an indirect relationship of financial literacy on the firm practice of book keeping, the usefulness of SMEs managers understanding of financial information collection, processing, storage and dissemination is of utmost importance. Firm managers well placed on the knowledge and skills of process financial data electronically will have timely information as a base for their present and future decision.

The model also offers significant results of the relationship of financial literacy and firm risk management practices. As it is demonstrated in [8], [45], [46], risk management is an important firm determinant of financial literacy. Therefore firm managers high level of financial literacy will embark on more effective business insurance and internal risk management practices and strategies. The lack of insurance cover by micro entrepreneurs demonstrated in [8], verify the failure of these SME managers to recognize the its importance.

Well placed firm practice of data management has been shown to have a high significance on the performance of the firm; the results are elucidated in $\mathrm{H}_{5}$. Proper book keeping is one of the firm sound accounting practices. Consistent with the result [61] offers more evidence that proper book keeping practices as the one of the key factor for SME success or failure in United Kingdom and Nigeria comparative study. And also [62] contended that majority of SMEs lacked accounting knowledge as a result they never kept complete accounting information therefore fail to effectively utilize financial data as basis for their decision and performance measurement. The use of technology in SMEs information processing has had a strengthening tie to firm performance as it shown in $\mathrm{H}_{7}$. Authors in [63] further stress on the importance of IT support and book keeping for entrepreneurs effort to maintain an efficient firm operation, if taken for granted could be a great hindrance for business success.

\section{CONCLUSION}

Coupled with the general impediment of information technology and financial system in developing economies, SMEs faces relatively copious challenges in terms of technology availability, awareness, and technical knowhow. Most of SMEs finds it is cost ineffective to monitor the present and updating to upcoming newer information technology versions which are emerging now and then. In addressing these challenges it is important to understand the relative impact of financial literacy and information technology on firm practices as it has been exemplified in this study. Situating SMEs owner/managers' financial knowledge and skills entwined with right technology adoption has an array of operational reinforcement of which if well understood and utilized will definitely enhance firm effective practices ultimately improve performance. Investment on SMEs risk management good practices and a good system of financial information collection, processing, keeping and dissemination has valuable tie with firm performance.

Limited by the nature of the study in terms of data and analytical approach, nevertheless the study gives glimpses of unharnessed benefits of integrating financial management and information technology in developing economy firms.

\section{FURTHER STUDY RECOMMENDATION}

There is much untapped potential of the applicability of technology adoption and its implications on awareness, access and actual use of financial products by individual and firms in developing economies. This study recommends more rigorous scientific research to be undertaken on this phenomenon including more variables of firm practices.

\section{REFERENCES}

[1] M. A. Aremu and S. L. Adeyemi, "Small and medium scale enterprises as a survival strategy for employment generation in Nigeria," Journal of sustainable development, vol. 4, p. 200, 2011.

[2] T. Forester, High-tech society: the story of the information technology revolution: Mit Press, 1987.

[3] B. Hobijn and B. Jovanovic, "The information-technology revolution and the stock market: Evidence," American Economic Review, vol. 91, pp. 1203-1220, 2001.

[4] D. Byrne, S. Oliner, and D. Sichel, "Is the information technology revolution over?," 2013.

[5] M. Iansiti and K. R. Lakhani, "Digital ubiquity:: How connections, sensors, and data are revolutionizing business," Harvard Business Review, vol. 92, p. 19, 2014. 
[6] A. Tarute and R. Gatautis, "ICT impact on SMEs performance," Procedia-Social and Behavioral Sciences, vol. 110, pp. 1218-1225, 2014.

[7] M. A. A. Kumar, "Financial Literacy awareness among SME's in Western Division of Fiji," EPH-International Journal of Educational Research (ISSN: 2208-2204), vol. 1, pp. 12-27, 2017.

[8] F. Olawale, "The financial literacy of Micro Enterpreneurs in South Africa," Journal of social sciences, vol. 42, p. 7, 2014.

[9] S. Wise, "The impact of financial literacy on new venture survival," International Journal of Business and Management, vol. 8, p. 30, 2013.

[10] A. Drexler, G. Fischer, and A. Schoar, "Keeping it simple: financial literacy and rules of thumb," American Economic Journal: Applied Economics, vol. 6, pp. 1-31, 2014.

[11] H. K. Mutegi, P. W. Njeru, and N. T. Ongesa, "Financial literacy and its impact on loan repayment by small and medium entrepreneurs," 2015.

[12] P. Datta, "A preliminary study of ecommerce adoption in developing countries," Information Systems Journal, vol. 21, pp. 3-32, 2011.

[13] E. F. Schumacher and S. I. Beautiful, economics as if people mattered: thesis, 1977.

[14] A. Atkinson and F.-A. Messy, "Measuring financial literacy," 2012.

[15] R. R. Nelson, An evolutionary theory of economic change: harvard university press, 2009.

[16] A. S. Bharadwaj, "A resource-based perspective on information technology capability and firm performance: an empirical investigation," MIS quarterly, pp. 169-196, 2000.

[17] T.-P. Liang, J.-J. You, and C.-C. Liu, "A resource-based perspective on information technology and firm performance: a meta analysis," Industrial Management \& Data Systems, vol. 110, pp. 1138-1158, 2010.

[18] R. Santhanam and E. Hartono, "Issues in linking information technology capability to firm performance," MIS quarterly, pp. 125-153, 2003.

[19] N. M. Menon, B. Lee, and L. Eldenburg, "Productivity of information systems in the healthcare industry," Information Systems Research, vol. 11, pp. 83-92, 2000

[20] M. Abreu and V. Mendes, "Financial literacy and portfolio diversification," Quantitative finance, vol. 10, pp. 515-528, 2010.

[21] S. Agarwal, G. Amromin, I. Ben-David, S. Chomsisengphet, and D. D. Evanoff, "Financial literacy and financial planning: Evidence from India," Journal of Housing Economics, vol. 27, pp. 4-21, 2015.

[22] P. Babiarz and C. A. Robb, "Financial literacy and emergency saving," Journal of Family and Economic Issues, vol. 35, pp. 40-50, 2014.

[23] S. A. Cole, T. A. Sampson, and B. H. Zia, Financial literacy, financial decisions, and the demand for financial services: evidence from India and Indonesia: Harvard Business School Cambridge, MA, 2009.

[24] D. A. Adomako S, "Financial Literacy and firm performance: the moderating role of financial capital availability and resource flexibility," International Journal of Management and Organizational studies, vol. 3, 2014.

[25] P. Dahmen and E. Rodríguez, "Financial literacy and the success of small businesses: An observation from a small business development center," Numeracy, vol. 7, p. 3, 2014.

[26] P. Chepngetich, "Effect of Financial Literacy and Performance SMEs. Evidence from Kenya," 2016.

[27] A. H. Seyal, M. Noah Abd Rahman, and H. Awg Yussof Hj Awg Mohammad, "A quantitative analysis of factors contributing electronic data interchange adoption among Bruneian SMEs: A pilot study," Business Process Management Journal, vol. 13, pp. 728-746, 2007.

[28] G. Lukianchuk, "The impact of enterprise risk management on firm performance of small and medium enterprises," European Scientific Journal, ESJ, vol. 11, 2015.

[29] F.-A. Messy and C. Monticone, "The status of financial education in Africa," 2012.

[30] M. Berisha-Namani, "The role of information technology in small and medium sized enterprises in Kosova," in Fulbright Academy Conference, 2009, pp. 1-8.

[31] A. Parasuraman, "Technology Readiness Index (TRI) a multiple-item scale to measure readiness to embrace new technologies," Journal of service research, vol. 2, pp. 307-320, 2000.
[32] N. Tsikriktsis, "A technology readiness-based taxonomy of customers: A replication and extension," Journal of Service Research, vol. 7, pp. 42-52, 2004

[33] Y. Pierrakis and L. Collins, "Crowdfunding: A new innovative model of providing funding to projects and businesses," 2013.

[34] URT, "Small and Medium Enterprises Development Policy," M. o. I. a. Trade, Ed., ed. Dar es Salaam, 2003.

[35] L. J. Servon and R. Kaestner, "Consumer financial literacy and the impact of online banking on the financial behavior of lower-income bank customers," Journal of Consumer Affairs, vol. 42, pp. 271-305, 2008.

[36] S. Bansal, "Perspective of technology in achieving financial inclusion in rural India," Procedia Economics and Finance, vol. 11, pp. 472-480, 2014.

[37] N. A. Rahman, Z. Yaacob, and R. M. Radzi, "An overview of technological innovation on SME survival: a conceptual paper," Procedia-Social and Behavioral Sciences, vol. 224, pp. 508-515, 2016.

[38] C. Chittithaworn, M. A. Islam, T. Keawchana, and D. H. M. Yusuf, "Factors affecting business success of small \& medium enterprises (SMEs) in Thailand," Asian Social Science, vol. 7, p. 180, 2011.

[39] Z. M. Makhbul and F. M. Hasun, "Entrepreneurial success: An exploratory study among entrepreneurs," International Journal of Business and Management, vol. 6, p. 116, 2010.

[40] O. M. Oyeku, O. Oduyoye, O. Asikhia, M. Kabuoh, and G. Elemo, "On entrepreneurial success of small and medium enterprises (SMEs): A conceptual and theoretical framework," Journal of Economics and Sustainable Development, vol. 5, pp. 14-23, 2014

[41] P. Fariselli, C. Oughton, C. Picory, and R. Sugden, "Electronic commerce and the future for SMEs in a global market-place: Networking and public policies," Small Business Economics, vol. 12, pp. 261-275, 1999.

[42] G. Premkumar and M. Roberts, "Adoption of new information technologies in rural small businesses," Omega, vol. 27, pp. 467-484, 1999.

[43] A. A. Eniola and H. Entebang, "SME firm performance-financial innovation and challenges," Procedia-Social and Behavioral Sciences, vol. 195, pp. 334-342, 2015.

[44] S. N.-I. M. Kamal, N. H. M. Yatim, S. Osman, M. N. Ali, N. M. Ali, and J. M. Jali, "Developing the Authenticity Framework of Electronic Business Records in SMEs Companies," Procedia Economics and Finance, vol. 31, pp. 834-838, 2015.

[45] K. W. Hollman and S. Mohammad-Zadeh, "Risk management in small business," Journal of Small Business Management, vol. 22, pp. 47-55, 1984.

[46] S. J. Huston, "Measuring financial literacy," Journal of Consumer Affairs, vol. 44, pp. 296-316, 2010.

[47] C. M. Lau and K. Roopnarain, "The effects of nonfinancial and financial measures on employee motivation to participate in target setting," The British accounting review, vol. 46, pp. 228-247, 2014.

[48] D. Garson, Partial Least Square: Regression and Structural Equation Models. North Carolina State University: Statistical Associates 2016.

[49] W. W. Chin, "The partial least squares approach to structural equation modeling," Modern methods for business research, vol. 295, pp. 295336, 1998.

[50] O. Götz, K. Liehr-Gobbers, and M. Krafft, "Evaluation of structural equation models using the partial least squares (PLS) approach," in Handbook of partial least squares, ed: Springer, 2010, pp. 691-711.

[51] J. F. Hair, M. Sarstedt, C. M. Ringle, and J. A. Mena, "An assessment of the use of partial least squares structural equation modeling in marketing research," Journal of the academy of marketing science, vol. 40, pp. 414433, 2012.

[52] J. Hulland, "Use of partial least squares (PLS) in strategic management research: A review of four recent studies," Strategic management journal, pp. 195-204, 1999.

[53] M. Höck and C. M. Ringle, "Strategic networks in the software industry: An empirical analysis of the value continuum," in IFSAM VIIIth World Congress, 2006, p. 2010. 
[54] J. Henseler, C. M. Ringle, and M. Sarstedt, "A new criterion for assessing discriminant validity in variance-based structural equation modeling," Journal of the Academy of Marketing Science, vol. 43, pp. $115-135,2015$

[55] T. S. Teo, S. C. Srivastava, and L. Jiang, "Trust and electronic government success: An empirical study," Journal of management information systems, vol. 25, pp. 99-132, 2008.

[56] A. H. Gold, A. Malhotra, and A. H. Segars, "Knowledge management: An organizational capabilities perspective," Journal of management information systems, vol. 18, pp. 185-214, 2001.

[57] P. M. Podsakoff, S. B. MacKenzie, J.-Y. Lee, and N. P. Podsakoff, "Common method biases in behavioral research: a critical review of the literature and recommended remedies," Journal of applied psychology, vol. 88, p. 879, 2003.

[58] N. Kock, "Common method bias in PLS-SEM: A full collinearity assessment approach," International Journal of e-Collaboration (IJeC), vol. 11, pp. 1-10, 2015.
[59] N. Podsakoff, "Common method biases in behavioral research: A critical review of the literature and recommended remedies," Journal of Applied Psychology, vol. 88, pp. 879-903, 2003.

[60] K. Saira, M. A. Zariyawati, and M. N. Annuar, "Information system and firms' performance: the case of Malaysian small medium enterprises," International business research, vol. 3, p. 28, 2010.

[61] U. B. Ihua, "SMEs key failure-factors: a comparison between the United Kingdom and Nigeria," Journal of Social Sciences, vol. 18, pp. 199-207, 2009.

[62] N. Maseko and O. Manyani, "Accounting practices of SMEs in Zimbabwe: An investigative study of record keeping for performance measurement (A case study of Bindura)," Journal of accounting and taxation, vol. 3, p. 158, 2011.

[63] E. G. Carayannis and M. Von Zedtwitz, "Architecting gloCal (globallocal), real-virtual incubator networks (G-RVINs) as catalysts and accelerators of entrepreneurship in transitioning and developing economies: lessons learned and best practices from current development and business incubation practices," Technovation, vol. 25, pp. 95-110, 2005. 